Proc. Indian Acad. Sci. (Earth Planet. Sci.), Vol. 90, Number 2, July 1981, pp. 161-172, (c) Printed in India.

\title{
Thermoluminescence dating of pottery from Sringaverapura-A Ramayana site
}

\author{
D P AGRAWAL, N BHANDARI, B B LAL* and A K SINGHVI \\ Physical Research Laboratory, Ahmedabad 380 009, India \\ *Indian Institute of Advanced Study, Simla 171 005, India \\ MS received 16 August 1980; revised 9 April 1981
}

\begin{abstract}
The first thermoluminescence (TL) dates of pottery from a Ramayana associated site are reported. The TL dates for pre-NBPW Black-Slipped Ware levels are 730 and 765 B.C., while radiocarbon date takes the earliest Black Slipped Ware level (for which no TL dates are available) to 905 B.C. (uncorrected). For the OCW level, three TL dates are available which range from 1035 B.C. to 875 B.C. The early NBPW period believed to be associated with the Ramayana episode will thus be post-750 B.C.
\end{abstract}

Keywords. Thermoluminescence dates; fine grain technique; Ramayana; Sringaverapura; archaeology.

\section{Introduction}

An attempt was made by Lal (1979) to find a common archaeological denominator for the Ramayana associated sites so that the material culture contemporary to the epic may be identified and dated. Though about fifteen hundred archaeological ${ }^{14} \mathrm{C}$ dates are available today (Agrawal et al 1975), many archaeological sites still remain undated primarily due to paucity of datable organic material. We have now installed a thermoluminescence (TL) laboratory and have taken up a systematic study of the important sites where radiocarbon method could not be applied so far.

Sringaverapura is a site associated with the Ramayana and has been excavated recently. All the Ramayana associated sites, viz. Ayodhya, BharadwajaAshrama and Nandigrama, have yielded an early Northern Black Polished Ware (NBPW) level. This level is now thought to be coeval with the Ramayana period (Lal 1981). At Sringaverapura, however, the NBPW level is preceded by a Black-Slipped Ware level which in turn, is preeeded by that of Ochre Colour Ware (OCW).

The OCW culture is a controversial one and there is as yet no unanimity about its authorship (Agrawal 1969; Lal 1972). There are till today no radiocarbon dates available from unambiguous OCW levels. TL dates of some other debated OCW sites are available (Huxtable et al 1972) (table 1), however, these indicate a large scatter from $c .2600$ to 1100 B.C. and therefore cannot be used for pinpointing a date bracket for the OCW culture. It should, however, be noted that these TL measurements were made in 1969 and no sherds were 
tested for anomalous fading at that time. Also most of the sherds emanated radon so that the dose would have been over-estimated, because the full implication of this had not been realized then. The dates should therefore be regarded as minimum ages for the culture ( $J$ Huxtable, personal communication).

\section{Sample collection and site details}

The site [Sringaverapura mound] is situated $35 \mathrm{~km}$ upstream from Allahabad. The mound is situated on the bank of River Ganga. A detailed excavation

Table 1. TL dates from various OCW sites as reported by Huxtable et al 1972 .

\begin{tabular}{lccl}
\hline Site & $\begin{array}{l}\text { Sherd } \\
\text { No. }\end{array}$ & $\begin{array}{l}\text { TL ages } \\
\text { (years B. C.) }\end{array}$ & $\begin{array}{c}\text { Mean TL age } \\
\text { (years B. C.) }\end{array}$ \\
\hline Atranjikhera & 11164 & 1610 & \\
& 11165 & 1170 & 1690 \\
& C1 & 2280 & \\
Lal Qila & C3 & 1250 & 1880 \\
& 11291 & 2130 & \\
Hhinjhana & 92 & 1730 & 2070 \\
& 11392 & 2030 & \\
& B1 & 1990 & 1340 \\
Nasirpur & B2 & 1570 & \\
& 11491 & 2650 & 1500 \\
\hline
\end{tabular}

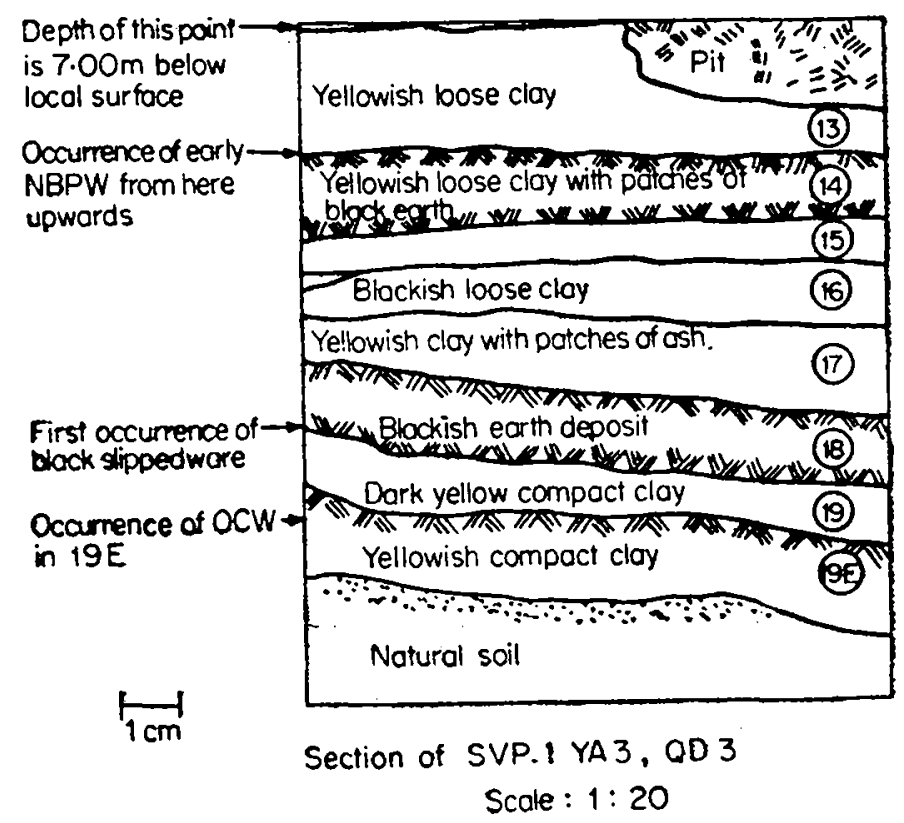

Figure 1. Section diagram along with cultural association of trench SVP 1, at Sringaverapura. 
yielded archaeologic material belonging to seven different cultural periods in a total deposit of nearly $9 \mathrm{~m}$ below the top surface (figure 1).

The pre-NBPW level was spread over a $1.65 \mathrm{~m}$ thick deposit of which OCW and Black-Slipped Ware were 0.45 and $1.2 \mathrm{~m}$ respectively. The pre-NBPW deposits gave red ware and black-slipped ware, the $O C W$ deposit yielded a red ware of OCW culture. A reliable sampling and site details are crucial for TL dating and, with this in view, the samples were collected at the site by the authors (B B Lal and A K Singhvi) during the excavations at Sringaverapura. All the samples were carefully identified and were immediately sealed with adhering soil in double plastic bags. This method enabled effective retention of moisture which was subsequently determined in the laboratory.

\section{Thermoluminescence analysis}

The basic principles of TL dating and its application to archaeology have been described in detail by Singhvi and Nambi (1979). We briefly describe here the various parameters used in TL age determination.

\subsection{The age equation}

The minerals responsible for the TL of the samples lose their geologic TL during the firing of pottery. A fresh acquisition of $T L$ restarts due to the exposure of the sample to radiation arising from natural radioactivity (uranium and thorium series and potassium) present in the sample matrix and the burial media. The TL measured in the laboratory is simply related to the time elapsed since firing of the samples as the annual dose rate is practically constant.

The age determination thus is based on: (a) the measurement of the total radiation dose via $\mathrm{TL}$ and (b) the measurement of radiation dose rate. The age equation can be written as:

$$
\text { Age }=\frac{\text { Natural TL (i.e. total radiation dose) }}{\text { TL per unit radiation dose } \times \text { dose per year }}
$$

which can be expressed as:

$$
\begin{aligned}
& \text { Age }=\frac{(\mathrm{ED})_{\beta}+I}{a \mathrm{D}_{\alpha}+\mathrm{D}_{\beta}+\mathrm{D}_{\gamma}+\mathrm{D}_{\mathrm{c}}}, \\
& \text { where }(\mathrm{ED})_{\beta}=\frac{\text { Natural } \mathrm{TL}}{(\mathrm{TL} \text { per unit radiation dose })_{\beta}}, \\
& I=\text { supralinearity correction, } \\
& a=(\mathrm{TL} \text { per rad })_{\alpha} /(\text { TL per rad })_{\beta} .
\end{aligned}
$$

D's represent dose rates due to various radiation components arising from the decay of natural U-238, Th-232 series and $K-40$ present in varying degrees 


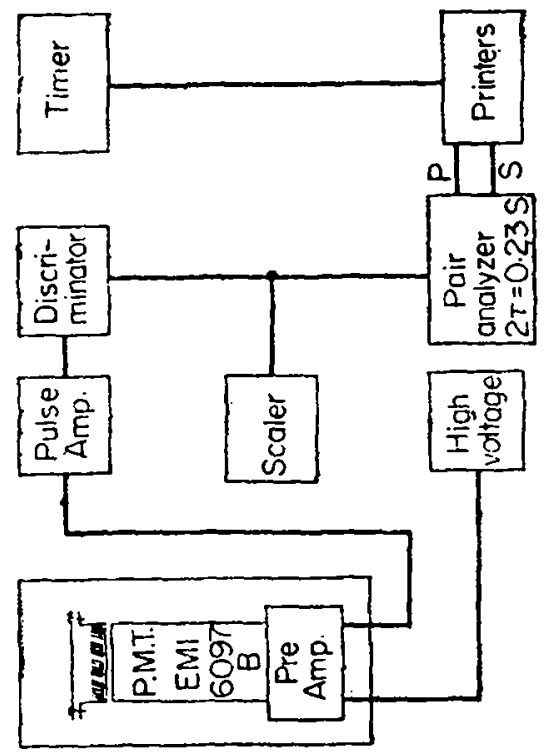

- $\stackrel{0}{5}$
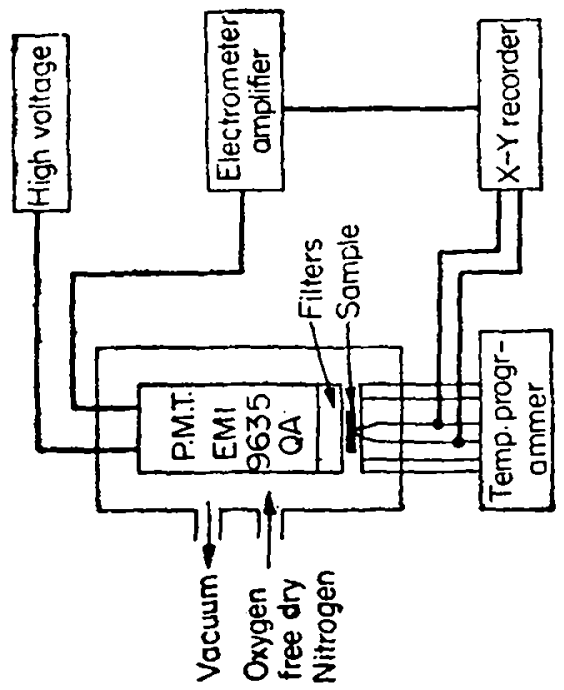

亭

$\frac{\pi}{\frac{2}{2}}$

로

苟

g

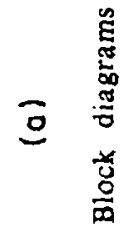

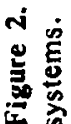

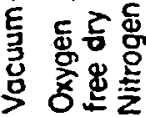


in pottery $(\mathrm{P})$ and soil $(\mathrm{S})$. The various contributions to these dose rates are:

$$
\begin{aligned}
& D_{\alpha}=D_{\alpha}^{p}(T h, U), \\
& D_{\beta}^{p}=D_{\beta}^{p}(T h, U)+D_{\beta}^{p}(K), \\
& D_{\gamma}=D_{\gamma}^{s}(T h, U)+D_{\gamma}^{s}(K), \\
& D_{c}=D_{c} \text { (cosmic rays). }
\end{aligned}
$$

Here, typically $D_{\beta}^{p}(K)$ is the contribution to beta dose from the beta decay of K-40 present in the pottery matrix. The scaling factor $a$ described above takes into account the lower TL induction efficiency of alphas compared to that of betas.

\subsection{Experimental details}

Low light levels encountered in archaeologic ceramics put exacting requirements on the sample preparation and measurement techniques. A considerable effort was therefore put into the fabrication of TL vacuum glow oven and the electronics to ensure reliable TL measurement with negligible interference from spurious TL, etc. In what follows we describe the various procedures as also the intercalibration exercises carried out in our laboratory to ensure a reliable TL date. A schematic diagram of the TL apparatus and the alpha counting system is given in figure 2. Typical glow curves are indicated in figure 3.

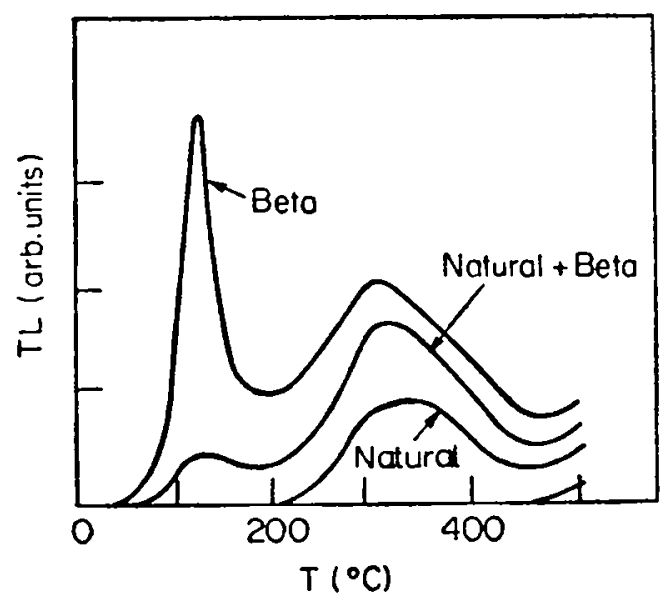

Figure 3. Typical TL glow curve of fine grain extracts from potsherds excavated from Sringaverapura. 


\section{2 a. $T L$ reader}

The TL reader comprised of a vacuum glow oven fabricated by us. The heater was a $0.25 \mathrm{~mm}$ thick kanthal strip with a flexible power supply contact to avoid any possible warp due to extension of the plate during heating. The solid angle of the sample subtended at the photocathode was frequently monitored using a $\mathrm{CaF}_{2}$ : natural phosphor disc. All the measurements were made after evacuating the oven chamber twice and flushing with ultra high purity nitrogen gas (IOLAR-Grade II supplied by the Indian Oxygen). Nitrogen flow rate was kept at about 3-3.5 1/min since lower flow rates occasionally failed to quench the spurious TL. The temperature was controlled using an automatic linear temperature programmer (Devgan et al 1980). The reproducibility and linearity of heating rate was checked frequently during the measurements using a Hewlett Packard time base AM 171008. Typical heating rates were usually $6-7^{\circ} \mathrm{C} / \mathrm{sec}$ and the reproducibility was better than $1 \%$ throughout the measurement schedule. The optical detection system comprised of an EMI 9635QA (selected for high blue to low red sensitivity) coupled to Corning 7-59 and 5-60 filters along with two Chance Pilkington HA3 filters. This arrangement gave a good discrimination against black-body radiation upto $500^{\circ} \mathrm{C}$. The PMT output was amplified through a PRL fabricated electrometer amplifier using a CK5886 electrometer tube. The stability of the optics channel was continuously monitored using a radiocarbon activated plastic phosphor (Facey 1966) and was better than $\pm 1.5 \%$.

\section{2 b. Radiation sourc es}

Artificial beta irradiations were carried out using a $40 \mathrm{mCi}{ }^{90} \mathrm{Sr} /{ }^{90} \mathrm{Y}$ beta plaque source (type SIP). The beta irradiations were carried out 'off' plate and the irradiation facility consisted of a $1.52 \mathrm{~cm}$ high aluminium irradiation mount on a perspex base. The primary calibration of the beta source was done using irradiated $\mathrm{CaF}_{2}$ : nat disc obtained from Research Laboratory for Archaeology, Oxford. This was recalibrated at the Bhabha Atomic Research Centre, Bombay, where the values agreed to within $4 \%$. The dose rate to $\mathrm{CaF}_{2}$ : nat was found to be $121 \cdot 3 \mathrm{rads} / \mathrm{min}$. The dose to pottery was taken to be 1.05 times the dose to $\mathrm{CaF}_{2}$ : nat (Wintle and Murray 1977).

Artificial alpha irradiations were carried out in six-seater vacuum alpha irradiation facility (Singhvi and Aitken 1978). The calibration of alpha source was done at Oxford via alpha spectrometry and by intercomparing irradiated discs of $\mathrm{CaF}_{2}$ :nat. The average source strength as seen by the sample was $S=$ $0.080 \mu \mathrm{m}^{-2} \mathrm{~min}^{-1}$.

\section{3-2 c. Sample radioactivity}

The natural radioactivity $i$. e. U-238 and Th-232 was estimated using thick source $\mathrm{ZnS}(\mathrm{Ag})$ alpha counting technique (Turner et al 1958). Plastic screens impregnated with $\mathrm{ZnS}$ (Ag) were used as scintillators. A fixed $42 \mathrm{~mm}$ dia counting area was defined by a steel ring of appropriate dimensions. An EMI 
6097B photomultiplier tube coupled to a single channel spectrometer was used as counting system. The system also had a pair counting facility with resolving time of $0.23 \mathrm{sec}$. This enabled check on abnormal U/Th ratios by measuring ${ }^{216} \mathrm{Po}$ alpha activity (half life $0.15 \mathrm{sec}$ ). A serial printer printed out the data every twenty minutes and this ensured a check against any electrical disturbance or on any count raté charge due to system malfunctioning. The spectrometer was calibrated using two Canadian certified reference material standards BL-3 ( $1 \% \mathrm{U})$ and DL-1 (41 ppm U, $83 \mathrm{ppm}$ Th). The $83 \%$ discrimination level was adjusted using BL-3. Typical background count rates were $0 \cdot 1-0 \cdot 2$ counts $/ \mathrm{ksec} . \mathrm{cm}^{2}$ and the pottery count rates were approximately 15 counts/ ksec. $\mathrm{cm}^{2}$. In all the samples both unsealed $\left(x_{0}\right)$ and sealed $\left(\alpha_{1}\right)$ counts were done to check the loss of radioactivity due to radon escape. As in all the cases $\alpha_{0}$ and $\alpha_{1}$ were almost identical within $7 \%$, we used $\alpha_{0}$ for estimating $U$ and Th concentration. Equal alpha activity was assumed in estimating the concentrations of $U$ and Th. Pairs rate was only used as a monitor for abnormal $\mathrm{U} / \mathrm{Th}$ ratios. The potassium analyses were carried out using a Perkin-Elmer 305A atomic absorption spectrophotometer. The sample was dissolved by a sequential treatment of $\mathrm{HF}, \mathrm{HClO}_{4}, \mathrm{HNO}_{3}, \mathrm{HCl}$. The potassium content of soll was determined by $\gamma$-ray spectrometry using a well type $7.5 \times 7.5 \mathrm{~cm} \mathrm{NaI}(\mathrm{Tl})$ scintillation system. A considerable variation in soil potassium content was observed within each stratum. Therefore an average value has been used for all the samples.

The estimation of dose rates from measured alpha count rates and potassium concentration was made using conversion factors given by Aitken (1979). Appropriate wetness corrections were also applied as described later.

\section{Measurements}

\subsection{Sample preparation}

The measurements reported here were carried out on the fine grain extract $(1-8 \mu \mathrm{m})$ from the pottery (Zimmerman 1971). A small portion of the sherd was gently crushed in a stainless steel V-trough, and the fraction less than $100 \mu \mathrm{m}$ was sieved out. $1-8 \mu \mathrm{m}$ grains were extracted from this fraction by their known sedimentation rates $(2-20 \mathrm{~min}$.) in a $6 \mathrm{~cm}$ analar grade acetone column. These grains were resuspended in acetone and equal volume of the suspension was pipetted on to clean aluminium discs (1 cm dia.) having $1 \mathrm{~cm}$ column of acetone above them. For each sample, 24 discs were prepared and all the sample preparations were carried out in lights filtered with three amber solar screens. The disc-to-disc variation of TL signal was typically $3-4 \%$.

\subsection{Estimation of $E D_{\beta}, I$ and $a$}

The equivalent beta dose was measured using additive beta dose procedures. In this, four discs were used for estimation of natural TL level, three each for natural plus beta-1 and natural plus beta-2. A growth curve of TL $v s$ applied dose was constructed and a linear back extrapolation of this growth 
curve yielded the equivalent beta dose. The value of the supralinearity intercept was also determined using the same procedure. Care was, however, taken to ensure that only samples with exactly similar radiation and thermal history were used (to avoid complications due to possible predose effect and transparency changes). The same procedure was used to construct alpha growth curve, yielding equivalent alpha exposure. The $a$ value was calculated using the relation given by Aitken and Bowman (1975).

$$
a=\frac{(\mathrm{ED})_{\beta}}{1300 \times \mathrm{S} \times \mathrm{Y}},
$$

where $S$ is the source strength and $\mathrm{Y}$ is the equivalent alpha exposure in minutes.

\subsection{Fading tests}

Plateau test for stability of TL signal in all the samples was carried out and the plateau $R$ varied from $\pm 3 \%$ to $\pm 7 \%$ in samples over a temperature range of $75-125^{\circ} \mathrm{C}$, beginning usually at around $275-300^{\circ} \mathrm{C}$. In addition, all the samples were measured for short-term anomalous fading (Wintle 1973) and the results indicated in table 2 .

\subsection{Age calculations}

The dry dose were then converted to wet dose rate using scaling relations given by Zimmerman (1971) giving true in situ dose rate. In situ water fraction was taken to be the realistic water fraction as the general stratigraphy, the depth of the samples $(9 \mathrm{~m})$ and the proximity of a river did indicate that water fraction did not vary appreciably during burial history of the sample. Typical saturation water content was $10 \%$ and thus a $\frac{1}{2}+\frac{1}{2}$ water content assumption would at best affect the age estimate only by $1-2 \%$. The dose rates with alpha components appropriately scaled down were added to obtain the total annual dose. In this calculation the cosmic ray contribution was taken to be $15 \mathrm{mr} / \mathrm{yr}$. The total archaeological dose $\left(\mathrm{ED}_{\beta}+\mathrm{I}\right)$ when divided by this dose rate gives the age.

\subsection{Estimation of errors}

The errors were assessed by a rigorous use of the procedures suggested by Aitken (1976) and Aitken and Alldred (1972). Typical measurement errors $i$. $e$. $(\delta Q / Q),(\delta I / Q+I),(\delta a / a)$ have been taken to be $5 \%$. The random errors in alpha counting and potassium determination were taken to be $5 \%$. The alpha and beta source calibration errors have also been taken as $\pm 5 \%$. Other errors due to variation in $\mathrm{Th} / \mathrm{U}$ ratio and wetness correction have been taken into account. Since a conservative estimate of errors due to all these parameters has been made, the quoted errors provide a maximal variation in the age. 


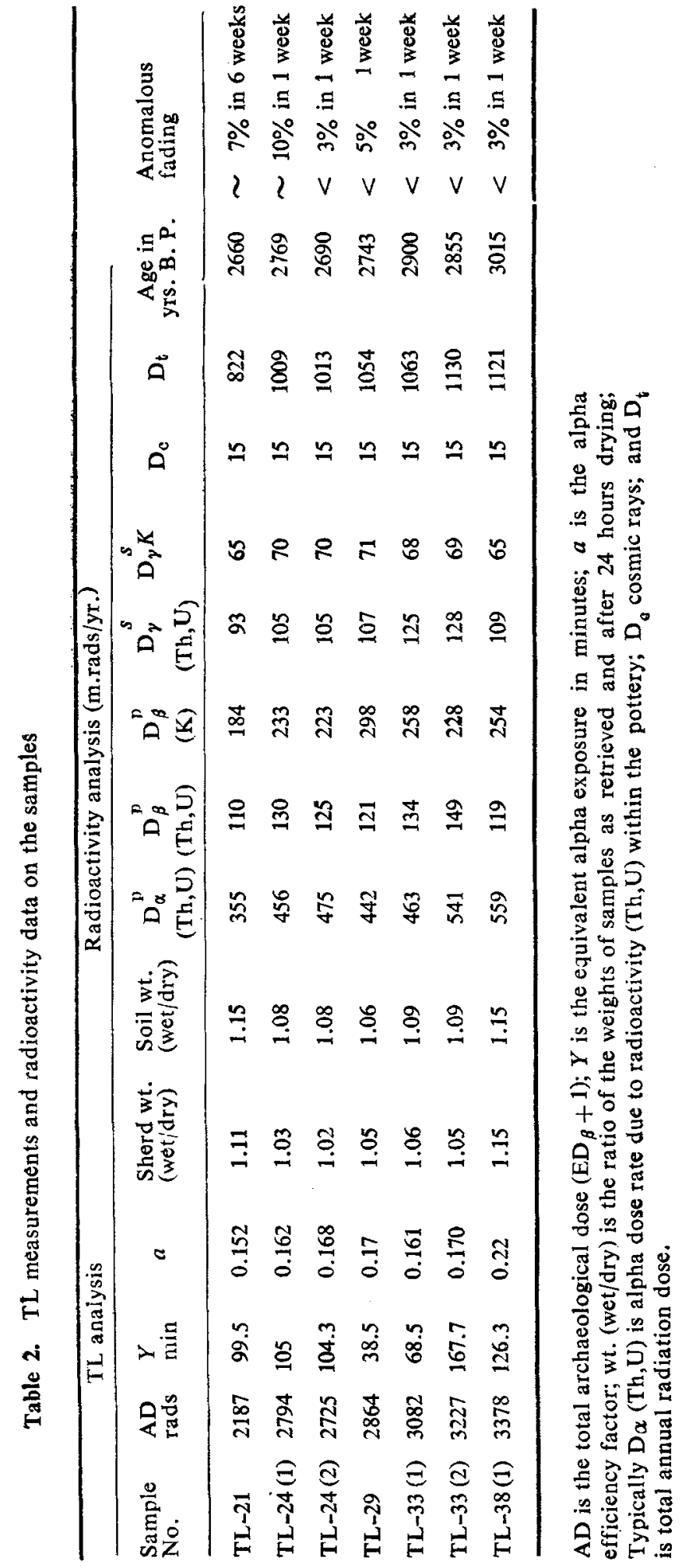




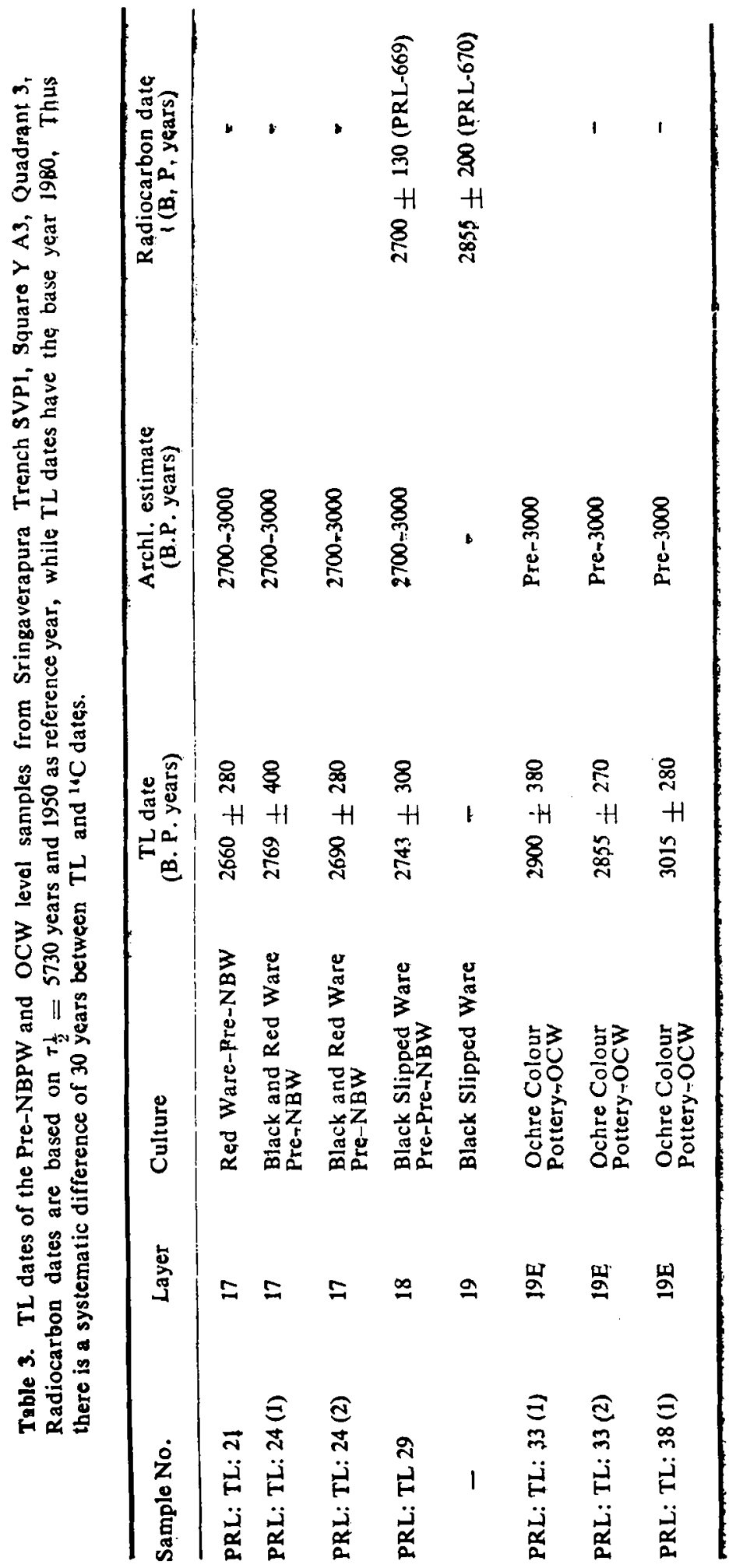




\section{Results and discussion}

Table 2 summarizes the sample data on TL and radioactivity measurements. Table 3 gives the sample parameters and TL dates. Archaeological and radiocarbon dates on samples from the same stratum are also included for comparison. All these dates show a good agreement, within the experimental errors. The TL dates, PRL: TL: 29, $763 \pm 300$ B.C. and radiocarbon date, $750 \pm 130$ B. C. for the same level agree very well. The TL dates also show a stratigraphic sequence with depth. The errors quoted are conservative estimates. Anomalous fading data are concordant with glow curve shapes (glow peaks at $110^{\circ} \mathrm{C}$ and $375^{\circ} \mathrm{C}$ ) and it appears that most of the TL is contributed by quartz (Singhvi and Zimmerman 1979). It is, however, difficult to reconcile this with the high values of $a$ (table 2) (Singhvi 1981).

Archaeologically, in the upper Ganga valley the Ochre colour ware has been thought to belong to the second half of the second millennium B. C. Thus, TL dates for $\mathrm{OCW}$ in the middle Ganga valley towards the end of that millennium may not be far out, particularly because there is considerable margin of error in the TL dates themselves. The date for the Black-Slipped occupation at Sringaverapura is $c .760 \mathrm{~B}$. C. These too seem to be fairly in order, allowing the same margin of error as in the case of OCW level which is datable to c. 950 B. C. Since the NBPW overlapped with the black-slipped ware at Sringaverapura, the beginning of the NBPW may well go back to the 7 th- 8 th century B. C. As already discussed earlier, the lowest common culture at the Ramayana sites so far excavated is that of the early NBPW. It would thus follow that the Ramayana episode is unlikely to be earlier than the middle of the eighth century B. C. This problem is discussed elsewhere in detail (Lal 1980).

\section{Acknowledgements}

We are grateful to Prof. D Lal for his kind interest in our TL laboratory. We are also thankful to Prof. M J Aitken for his invaluable help and encouragement in our TL programme, as also for the gift of a six-seater vacuum alpha irradiation facility and numerous other useful items. We also thank the Ford Foundation (India) for a generous financial assistance. We thank Dr D J Huntley for his kind gift of BL-3 and DL-1, Canadian reference material. We acknowledge the help received from the Electronics Laboratory, PRL. Our special thanks are due to $M / s$ N R Manchanda, A R Pandian and G T Panchal for their cooperation and $\mathrm{N}$ Hussain and $\mathrm{P}$ Sharma for their help in potassium analysis. We thank Miss Sheela Kusumgar for providing us the radiocarbon dates and Mr N B Vaghela for assistance.

\section{References}

Agrawal D P 1969 Asian Perspectives 12113

Agrawal D P, Kusumgar S and Pant R K 1975 Physics News 61

Aitken M J 1976 Archaeometry 18233

Aitken M J 1979 PACT 218

Aitken M J and Alldred J C 1972 Archaeometry 14257 
Aitken M J and Bowman S G E 1975 Archaeometry 17132

Devgan D P, Mazumdar H S and Singhvi A K 1980 J. Phys. E13 1347

Facey R A 1966 J. Sci. Instrum. 43658

Huxtable J, Zimmerman D W, Hasan S N and Gaur R C 1972 Antiquity 4662

Lal B B 1972 Antiquity 46282

Lal B B 1979 Project Report, Indian Institute of Advanced Study, Simla

Lal B B 1981 Antiquity (in press)

Singhvi A K 1981 Ancient T $L$ No. 1411 (in press)

Singhvi A K and Aitken M J 1978 Ancient T L 32

Singhvi A K and Nambi K S V 1979 Bull. Rad. Prot. 289

Singhvi A K and Zimmerman D W 1979 Archaeometry 2173

Turner RC, Radley J M and Mayneord W V 1958 Br. J. Radiol. 31397

Wintle A G W 1973 Nature London 245143

Wintle A G W and Murry A S M 1977 Archaeometry 1997

Zimmerman D W 1971 Archaeometry 1329 